\title{
Moving Branded Statins to Lowest Copay Tier Improves Patient Adherence
}

Shih-Yin Chen, PhD; Sonali N. Shah, RPh, MBA, MPH; Yuan-Chi Lee, MS; Luke Boulanger, MA, MBA; Jack Mardekian, PhD; and Andreas Kuznik, PhD

\begin{abstract}
BACKGROUND: Statins are efficacious in reducing the risk of major cardiovascular events for both primary and secondary prevention, yet long-term adherence is poor. Their effectiveness could be compromised in actual practice when patients are not adherent to the treatments. Higher copayments have been shown to be associated with lower adherence to statins.

OBJECTIVE: To assess the effect on patient adherence of moving branded atorvastatin and rosuvastatin from the second to the first tier by a Medicare Part D plan sponsor.

METHODS: Pharmacy claims and eligibility records between July 1, 2009, and July 31, 2011, of Medicare Part D members not receiving the lowincome subsidy were analyzed. New atorvastatin and rosuvastatin users in January 2010 (2010 cohort) were compared with those in January 2011 (2011 cohort) after this formulary tier change (tier-reduction group). Adherence was defined by the proportion of days covered (PDC) over 6 months. The impact of tier reduction on adherence was evaluated via logistic regression for binary outcome $(P D C \geq 0.8)$ and generalized linear regression for continuous PDC by comparing the 2011 cohort with the 2010 cohort, adjusting for demographic and clinical characteristics. Other statin users ( $97 \%$ on generic statins) were also analyzed, serving as a nontierreduction comparator group.
\end{abstract}

RESULTS: We identified 12,437 members in the tier-reduction group. Between the 2010 and 2011 cohorts, mean PDC increased from 0.77 to 0.83 , and the proportion of members with high adherence increased from $62.0 \%$ to $72.9 \%$ (both $P<0.001$ ). After regression adjustment, members in the 2011 cohort were more likely to be adherent $(0 \mathrm{R}=1.68 ; 95 \% \mathrm{Cl}=1.55$ $1.82)$ and had a $5.9 \%$ increase in PDC $(P<0.05)$. There was no significant increase in adherence observed in the comparator nontier-reduction group.

CONCLUSION: Findings from this study suggest that financial incentives may improve medication adherence. Future studies should evaluate whether such formulary strategies improve long-term adherence and patient outcomes.

J Manag Care Pharm. 2014;20(1):34-42

Copyright $\odot 2014$, Academy of Managed Care Pharmacy. All rights reserved.

\section{What is already known about this subject}

- Statins are efficacious in reducing the risk of major cardiovascular events for both primary and secondary prevention, yet long-term adherence is poor.

- Statin effectiveness could be compromised in actual practice when patients are not adherent to the treatments.

- Higher copayments have been shown to be associated with lower adherence to statins.

\section{What this study adds}

- This study examined the impact of moving branded statins to the lowest copay tier in a Medicare Part D plan sponsor on patient adherence.

- After implementation, the adherence rate, defined as proportion of days covered (PDC) $\geq 80 \%$ over a 6 -month period, increased from $62.0 \%$ to $72.9 \%$, with an adjusted odds ratio of $1.68(95 \%$ $\mathrm{CI}=1.55-1.82)$

- There was a 5.9\% increase in PDC after adjusting for patient characteristics.

- Our findings concerning Medicare Part D beneficiaries not receiving the low-income subsidy add to the existing evidence derived from commercially insured populations demonstrating that lower copayment improves adherence to essential medications.

$\square$ vidence from randomized clinical trials suggests that statins are efficacious in reducing the risk of major cardiovascular events for both primary and secondary prevention, ${ }^{1-4}$ yet long-term adherence is poor. ${ }^{5-9}$ Several studies also reported suboptimal short-term adherence to statins, within 1 year of treatment initiation..$^{9-14}$ Their effectiveness could be compromised in actual practice when patients are not adherent to the treatments. ${ }^{15-17}$ Past studies have found that among statin users, statins were less effective in preventing subsequent cardiovascular events among those with poor adherence. ${ }^{12,18,19}$ Statin users with poor adherence also incurred higher health care resource use and costs. ${ }^{11,20}$ Given that higher copayments have been shown to be associated with lower adherence to statins, ${ }^{21-24}$ greater patient cost-sharing may unintentionally and adversely impact the use of and adherence to essential medications, such as statins. ${ }^{25}$

Effective on January 1, 2011, a large Medicare Part D plan sponsor, serving both low-income subsidy (LIS) members and non-LIS members, moved branded atorvastatin and rosuvastatin from the second tier (preferred brand tier) to the first tier (generic tier). With this formulary change, the out-of-pocket payments for those 2 statins shifted from a 25\%-30\% coinsurance or $\$ 35$ copayment to a $\$ 0-\$ 4$ copayment for a 30 -day supply with variation in copayment contingent on benefit region and plan design after meeting the deductible limit.

It is not common for health plans to place a branded product on the lowest tier where generic class medications exist. While 
it is natural to have a significant cost-sharing reduction when the patent expires and generics are introduced, this change to branded atorvastatin and rosuvastatin provided an opportunity to understand the association between lowering prescription copayments and adherence to branded products, which may help to inform formulary design when no generic equivalents are available. Unlike cost-sharing reductions caused by the availability of generic substitutes, which can only occur upon patent expiration, health plans could make a decision to reduce branded copayments at any time. In addition, although there are studies evaluating the impact of lowering copayment statin medication adherence, ${ }^{26-29}$ published data are limited in elderly patients. While two-thirds of cardiovascular events and more than $80 \%$ of cardiovascular mortality occur in the elderly population, ${ }^{30,31}$ statin adherence rates in this group, depending on baseline risk, have been reported at $25 \%-40 \%$ over the course of 2 years. ${ }^{8}$ It is, therefore, not surprising that only half of patients treated with lipid-lowering medication meet their low-density lipoprotein (LDL) treatment goal..$^{32}$ Furthermore, this population usually has a lower disposable income and potentially different price (e.g. copayment) elasticity of demand than adults of working age. ${ }^{33}$ Hence, from a policy perspective, it is important to understand to what extent this population's adherence behavior responds to financial incentive, which may help inform the management of modifiable cardiovascular risk factors and improve the quality of care.

With a naturalistic quasi-experimental design involving users of other statins not subject to such change as a comparator group, the objective of this study was to assess the impact of moving branded statins to the lowest copay tier, therefore lowering copayments, on patient adherence in non-LIS Medicare Part D beneficiaries. Since hypercholesterolemia is one of many asymptomatic conditions that are often associated with poor adherence, ${ }^{8}$ findings from this study may be useful for health plan administrators and policy makers to inform the design of strategies to improve outcomes and health management in the long run for patients and payers.

\section{Methods \\ Data Source}

We analyzed pharmacy claims and eligibility records from July 1, 2009, to July 31, 2011, from a Medicare Part D plan sponsor that provided prescription drug benefits to more than 1.9 million members in 2011. Data were encrypted and compliant with the Health Insurance Portability and Accountability Act, and the study was exempted from institutional review board review. The members were served by a pharmacy network consisting of both chain and independent pharmacies. The eligibility records contained information on monthly eligibility indicators, age, gender, and geographic region of residence. Pharmacy claims recorded medication name, National Drug Code, LIS status, dispense date, quantity and days supplied, dosage, and plan and patient paid amounts.

\section{Study Design and Sample Selection}

This study used a cross-sectional pre- and postdesign based on January 1, 2011-the date when the formulary change became effective (Figure 1). The population for evaluation consisted of new users of branded atorvastatin and rosuvastatin who were subject to this formulary change of tier reduction. To understand the impact of this change, new branded atorvastatin and rosuvastatin users prior to January 1, 2011 (2010 cohort), were compared with new branded atorvastatin and rosuvastatin users after January 1, 2011 (2011 cohort). To assess whether there might be unobservable changes between the 2 time periods, we also evaluated new users of other statins (i.e., simvastatin, lovastatin, pravastatin, fluvastatin, pitavastatin, simvastatin/ezetimibe, simvastatin/niacin, and lovastatin/niacin) and compared users prior to January 1, 2011 (2010 cohort), and users after January 1, 2011 (2011 cohort), as a comparator (nontier-reduction group).

We selected members aged 18 years or older if they had any statin prescription (simvastatin, lovastatin, pravastatin, fluvastatin, atorvastatin, rosuvastatin, pitavastatin, simvastatin/ ezetimibe, simvastatin/niacin, and lovastatin/niacin) between January 1, 2010, and January 31, 2010, for the 2010 cohort and between January 1, 2011, and January 31, 2011, as the 2011 cohort. The dispense date of the first observed statin prescription was denoted as the index date. Members were included if they had continuous enrollment 6 months prior to and after the index date. We excluded members with prescriptions for statins during the 6 months prior to the index date to ensure only new users of statins were selected into the study. Since the impact of the tier reduction on copayments is much smaller for LIS-eligible members, we also excluded members who received LIS on their statin prescriptions. Members were then stratified based on whether they received the branded statins that would be subject to the tier reduction of lowering copayment or not.

\section{Study Measures}

Medication adherence was examined using the proportion of days covered (PDC). ${ }^{19}$ Adherence was evaluated from the time the first statin prescription was filled (index date). PDC was calculated as the sum of the days-of-supply from prescription claims of the index statin product during 6 months post-index divided by 180 days. High adherence was defined as PDC $\geq 0.8$. Prescription supply covering days beyond 180 days was discarded. PDC was truncated at a maximum value of 1 . Patients who switched to other statin products were considered discontinuing the index statin.

Demographic characteristics including patient age, gender, and geographic region of residence were determined on the index date of statin initiation. To understand the health status, we calculated RxRisk score as a proxy. RxRisk score is a risk adjustment algorithm to predict health care costs based on automated pharmacy claims developed by Fishman et al. 


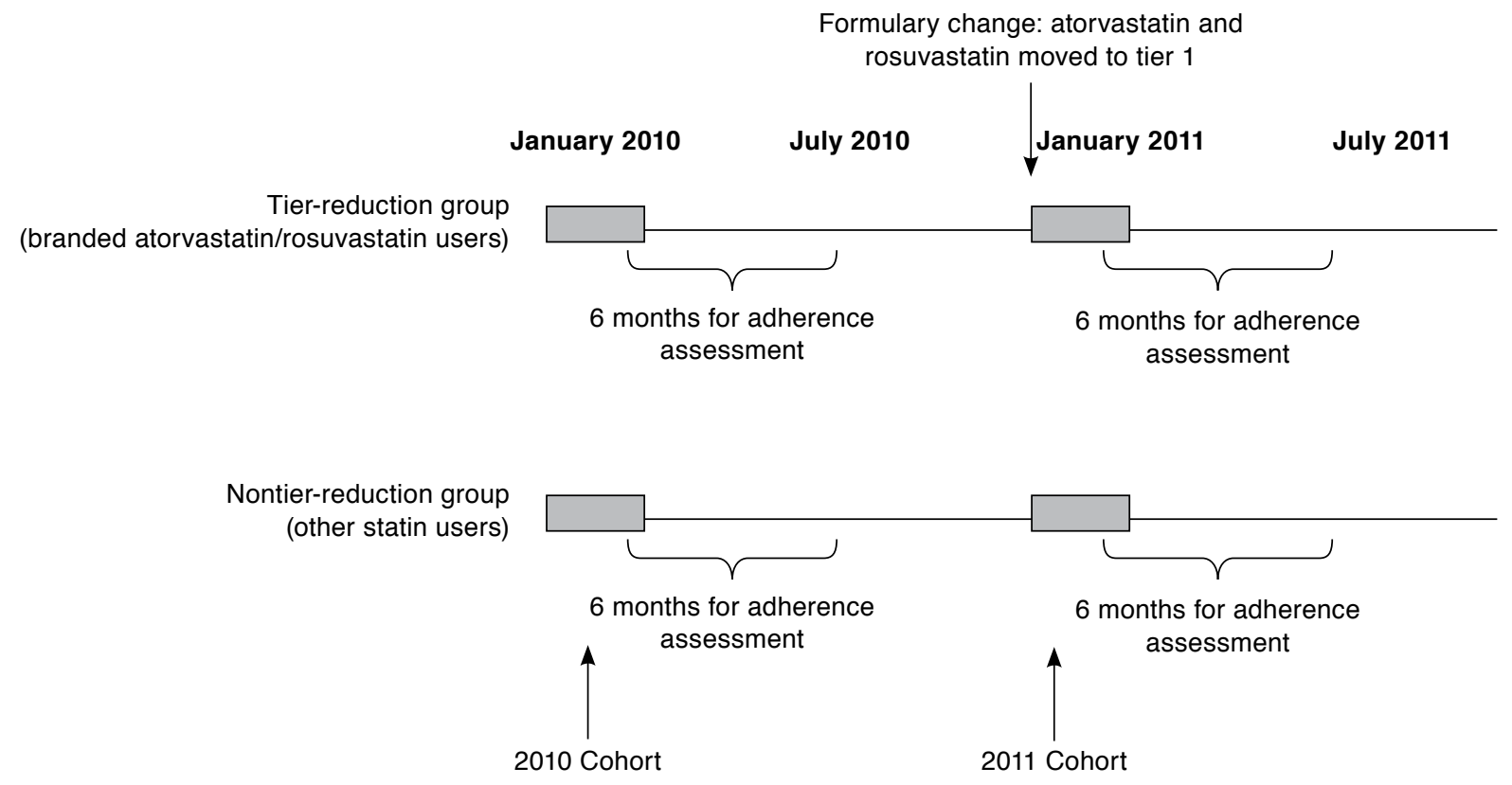

Process for selecting the tier-reduction group of branded atorvastatin and rosuvastatin users who initiated treatment between January 1 and January 31 . We compared their 6-month adherence prior to and after the formulary change. We also selected a nontier-reduction group as comparator.

(2003). ${ }^{34}$ Disease-specific weights were assigned according to the therapeutic agents used, as identified from pharmacy claims during 6 months prior to the index date. Patients were categorized into quartiles (RxRisk levels 1-4) based on their estimated RxRisk score, where the lowest quartile (RxRisk level 1) represented the lowest level of predicted costs. We calculated average 30-day copayments of statin prescription over the 6-month study follow-up period. Proportion of members reaching donut hole ( $\$ 2,830$ for 2010 and $\$ 2,840$ for 2011) at the 6-month follow-up period was also examined.

\section{Statistical Analysis}

Descriptive analyses for study measures were performed by comparing the 2010 cohort with the 2011 cohort for the tier-reduction group and the comparator group, respectively. Percentages were reported for categorical variables, and statistical differences were assessed using chi-square tests. Mean and standard deviations were reported for continuous variables, and statistical differences between the 2010 cohort and 2011 cohort were assessed using Student's t-tests.

We pooled branded atorvastatin and rosuvastatin users from 2010 and 2011 to assess whether there was an impact of tier reduction on statin adherence. We hypothesized that adherence in the 2011 cohort would be higher than the 2010 cohort if tier reduction had an impact on patient adherence. Logistic regres- sion models were used to examine the association between tier reduction and high adherence with a binary variable $\mathrm{PDC} \geq 0.8$ as 1 and $\mathrm{PDC}<0.8$ as 0 . In addition to evaluating adherence as a binary outcome, we also assessed it using PDC as a continuous variable. An ordinary linear regression model was fitted. All regression models were adjusted for patient age, gender, region, RxRisk score category, and percentage of patients with a supply of statin prescriptions for at least 90 days. For comparison purposes, similar regression analyses were conducted for the new users in the nontier-reduction group.

To ensure the estimates were robust, we conducted 2 sensitivity analyses regarding potential biases caused by the measurement approach and the data source. In the first sensitivity analysis, we excluded members who had statin prescriptions with a supply of 90 days or more. Since we assessed adherence using a 6-month period, having prescriptions with long days-of-supply decreased the chance to observe refill patterns to measure adherence. In the second sensitivity analysis, we excluded members with any statin prescription filled outside of retail, home, or outpatient settings (e.g., nursing home) in order to focus on patient behavior-related adherence. Members who filled the prescriptions in those settings may have been given the medications directly by health care providers, in which case we would not be assessing patient behavior-related adherence. 


\section{FIGURE 2 Sample Selection}

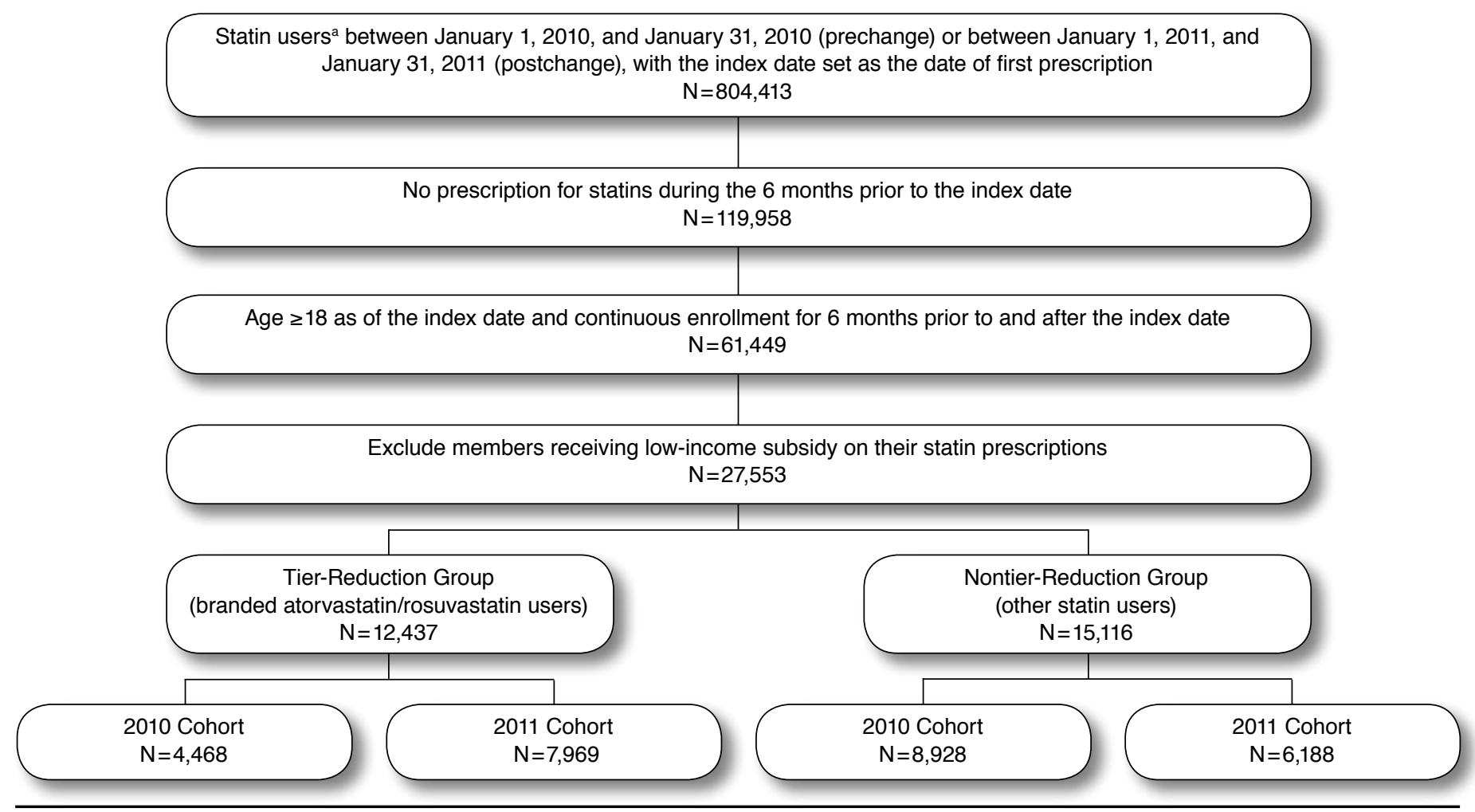

aProducts containing branded atorvastatin, fluvastatin, lovastatin, pravastatin, branded rosuvastatin, simvastatin, branded simvastatin/ezetimibe, branded simvastatin/ niacin, or branded lovastatin/niacin.

\section{Results}

\section{Member Characteristics}

This study identified 12,437 members in the tier-reduction group with 4,468 from 2010 and 7,969 from 2011 using branded atorvastatin and rosuvastatin (Figure 2). We also identified 15,116 members in the comparator nontier-reduction group with 8,928 from 2010 and 6,188 from 2011 using other statins. Most of the members (97\%) from the nontier-reduction group used generic statins.

The study population had a mean age of approximately 72 years, with a slightly older 2010 cohort (Table 1). Females accounted for approximately $64 \%$ of the study population. A great number of patients lived in the southern region, ranging from $38.1 \%$ to $48.3 \%$. In the tier-reduction group, the 2011 cohort showed a lower level of RxRisk score distribution compared with the 2010 cohort $(P<0.0001)$. A smaller proportion of the 2011 cohort hit the donut hole compared with the 2010 cohort $(36.4 \%$ vs. $41.0 \%$; $P<0.0001)$. On the other hand, in the nontier-reduction group, the 2011 cohort appeared to be slightly more ill, indicated by a distribution of RxRisk toward higher levels and $\$ 56.65$ to $\$ 35.81$ of members hitting the donut hole compared with the 2010 cohort. Across all groups, a higher proportion of members in the 2011 cohort had statin prescriptions with a 90-day supply. Over the 6-month observation period, the tier-reduction group experienced a substantial reduction in average 30-day statin copayment from $\$ 56.65$ to $\$ 35.81 \quad(P<0.0001)$. Meanwhile, since there was no tier change, the 2011 cohort in the nontier-reduction group had a small absolute change ( $\$ 7.89$ vs. $\$ 8.48 ; P=0.0263)$, though statistically significant, for average 30 -day statin copayments as expected.

\section{Statin Adherence}

In the tier-reduction group, the mean PDC over the 6-month study follow-up period increased from 0.77 to $0.83(P<0.001)$, and the proportion of members with high adherence (PDC $\geq 0.8$ ) increased from $62.0 \%$ to $72.9 \%(P<0.001)$ from the 2010 cohort to 2011 cohort (Figure 3). The nontier-reduction group had no significant change in mean PDC ( 0.77 to $0.78 ; P=0.326)$ and proportion of members with high adherence $(65.1 \%$ to $65.7 \% ; P=0.477$ ) between the 2 cohorts.

After adjusting for patient characteristics via logistic regressions, members from the 2011 cohort were more likely to have 


\section{TABLE 1 Member Characteristics}

\begin{tabular}{|c|c|c|c|c|c|c|}
\hline & \multicolumn{2}{|c|}{$\begin{array}{c}\text { Tier-Reduction Group } \\
\text { (Atorvastatin/Rosuvastatin Users) }\end{array}$} & \multirow[b]{2}{*}{$P$ Value } & \multicolumn{2}{|c|}{$\begin{array}{l}\text { Nontier-Reduction Group } \\
\text { (Other Statin Users) }\end{array}$} & \multirow[b]{2}{*}{$P$ Value } \\
\hline & 2010 Cohort & 2011 Cohort & & 2010 Cohort & 2011 Cohort & \\
\hline Number of members & 4,468 & 7,969 & & 8,928 & 6,188 & \\
\hline Age in years (\%) & & & $<0.001$ & & & 0.002 \\
\hline$<65$ & 13.7 & 16.6 & & 16.4 & 19.0 & \\
\hline $65-69$ & 13.6 & 18.1 & & 14.4 & 14.2 & \\
\hline $70-74$ & 19.9 & 23.4 & & 20.2 & 19.5 & \\
\hline $75-79$ & 17.6 & 17.3 & & 17.2 & 17.3 & \\
\hline $80-84$ & 16.1 & 12.0 & & 15.2 & 14.5 & \\
\hline $85+$ & 19.2 & 12.6 & & 16.7 & 15.5 & \\
\hline Age in years (mean [SD]) & 74.0 [12.9] & $71.6[13.1]$ & $<0.001$ & $73.0[13.4]$ & $72.1[13.7]$ & $<0.001$ \\
\hline Gender (\%) & & & 0.002 & & & 0.002 \\
\hline Male & 34.7 & 37.4 & & 34.8 & 37.2 & \\
\hline Female & 65.3 & 62.6 & & 65.2 & 62.8 & \\
\hline Region (\%) & & & $<0.001$ & & & $<0.001$ \\
\hline Northeast & 38.9 & 20.0 & & 26.0 & 25.3 & \\
\hline Midwest & 17.4 & 28.4 & & 23.3 & 21.4 & \\
\hline South & 38.1 & 45.6 & & 44.4 & 48.3 & \\
\hline West & 5.6 & 6.1 & & 6.3 & 5.0 & \\
\hline RxRisk score distribution (\%) & & & $<0.001$ & & & $<0.001$ \\
\hline Level 1 & 22.1 & 28.3 & & 22.5 & 21.2 & \\
\hline Level 2 & 34.1 & 33.8 & & 32.4 & 27.7 & \\
\hline Level 3 & 23.5 & 21.8 & & 23.8 & 24.2 & \\
\hline Level 4 & 20.3 & 16.0 & & 21.4 & 26.8 & \\
\hline $\begin{array}{l}\text { Proportion of patients reaching donut } \\
\text { hole at } 6 \text { months post-index }(\%)\end{array}$ & 41.0 & 36.4 & $<0.001$ & 38.8 & 45.2 & $<0.001$ \\
\hline Statin prescription with 90-day supply (\%) & 16.1 & 25.7 & $<0.001$ & 22.0 & 26.4 & $<0.001$ \\
\hline $\begin{array}{l}\text { Average } 30 \text {-day out-of-pocket payment } \\
\text { for statin prescriptions (mean [SD]) }\end{array}$ & $\$ 56.70[23.90]$ & $\$ 35.80[29.00]$ & $<0.001$ & $\$ 8.50[15.30]$ & $\$ 7.90[4.70]$ & 0.026 \\
\hline
\end{tabular}

high adherence to statins than those in the 2010 cohort (odds ratio $[\mathrm{OR}]=1.68 ; 95 \%$ confidence interval $[\mathrm{CI}]=1.55-1.82$ ) in the tier-reduction group (Table 2). We estimated the marginal probability to be a $5.3 \%$ increase from the predicted probability of $67.6 \%$ in the 2010 cohort to $72.9 \%$ in the 2011 cohort. No statistically significant changes were observed in the comparator nontier-reduction group ( $\mathrm{OR}=1.05 ; 95 \% \mathrm{CI}=0.98-1.12$ ). Across the models, older age was associated with higher odds of high adherence to statin therapy while poor health status, demonstrated by a higher level of RxRisk score, was associated with lower odds of high adherence. As expected, members receiving statin prescriptions with 90-day or more supply had higher odds of being adherent.

After fitting the continuous PDC with a generalized linear regression adjusting for patient characteristics, the adjusted difference in mean PDC between the 2011 cohort and 2010 cohort was estimated to be $5.9 \%(P<0.05)$ in the tier-reduction group (Figure 4). No change in the comparator nontier-reduction group was observed. The sensitivity analyses, similar analyses but excluding members with 90-day or greater supply of statin prescription and members who filled their statin prescription outside of retail, home, and outpatient settings, affirmed similar findings (Appendices A and B, available in online article).

\section{Discussion}

In 2011, a large Medicare Part D sponsor moved branded atorvastatin and rosuvastatin to the lowest tier. This retrospective cohort study examined the impact of this tier reduction on patient adherence using pharmacy claims data. In this sample of Medicare beneficiaries, we found a mean PDC of 0.78 over 6 months since treatment initiation and approximately $65 \%$ of patients with high adherence using PDC $\geq 0.8$ as the threshold. Two prior studies reported adherence to statins among new users over a 1-year period using the identical PDC measure. Yeaw et al. (2009) found a mean PDC of $0.61 .^{10}$ Vinker et al. (2013) found $38.9 \%$ of their statin initiators had PDC $\geq 0.8 .{ }^{9}$ It is not surprising that we found a higher mean PDC and a greater proportion of high adherent patients, since our evaluation period was shorter, and adherence has been found to decline over time. ${ }^{6}$ 


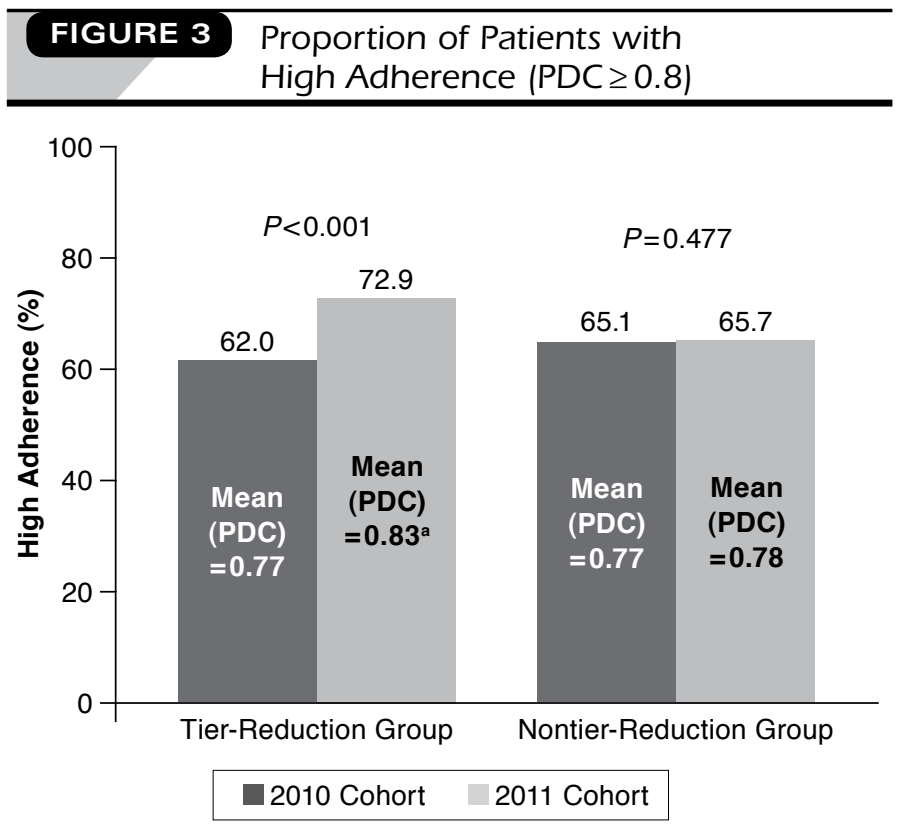

aP<0.05 between 2010 and 2011 cohorts.

$P D C=$ proportion of days covered.

Findings from this study suggest that this tier reduction associated with lower copayments had a positive effect on patient adherence. When evaluated in a dichotomous way (defined as PDC $\geq 0.8$ ), we observed an increase in adherence rate from $62.0 \%$ in 2010 to $72.9 \%$ in 2011 , representing a $68 \%$ increase in odds (OR $=1.68 ; 95 \% \mathrm{CI}=1.55-1.82)$. When evaluated as a continuous PDC measure, we observed an increase of $5.9 \%$. To understand whether there might be a time trend, this association was assessed in the nontier-reduction comparator group who experienced no reduction in copayments. We found no significant improvement in adherence over time in the comparator group. The design of this pre/post analysis with a comparator group strengthened the internal validity of our study.

Our findings are consistent with previous studies that demonstrated the association of reduced cost-sharing with better adherence to the medications..$^{26-29,35,36}$ A 5.9\% increase in PDC mirrors the reported data for statins from 3 previous studies. ${ }^{26,27,29}$ A study by Choudhry et al. (2010) showed copayment reduction according to a value-based insurance design (VBID) was associated with an immediate $2.8 \%$ increase in adherence to statins measured monthly using PDC. ${ }^{27}$ Chernew et al. (2008) also found a significant increase in medication possession ratio (MPR) of $3.39 \%$ MPR points to statins measured quarterly in participants of a VBID. ${ }^{26}$ Also using MPR over a 1-year period, Maciejewski et al. (2010) found an adjusted increase of MPR to be $2.56 \%$ in VBID participants. ${ }^{29}$
However, these studies mainly examined commercially insured populations that consisted of working adults and their dependants. To the best of our knowledge, this study is the first to assess the impact of reduced copayment on patient adherence in a Medicare population. More than 10 million elderly patients are estimated to be receiving statin therapy in the United States, ${ }^{32}$ and it is important to understand whether they bear the same price response. Cost-sharing strategies such as higher copayments, deductibles, and coinsurance based on tiers are often implemented by health plans to deter inappropriate or overuse of medications to control rising drug costs. ${ }^{37}$ These strategies may unintentionally and adversely impact the use and adherence to essential medications for chronic diseases. ${ }^{25}$ Medication adherence might be more challenging for the elderly population because of unique barriers such as multiple comorbidities, polypharmacy, and compromised physical and cognitive health. ${ }^{38}$ Nonadherence takes a greater toll on the elderly population with more serious consequences such as risk of complications, institutionalizations, or premature death from poor disease control. Our findings suggest that alleviating the financial barrier could be considered as a strategy to improve medication adherence in the elderly population.

In recent years, VBID has become popular to ensure that copayments are based on potential clinical benefits. ${ }^{39}$ Since legislation allowing Medicare to test VBID has been introduced, and VBID has been included in the Patient Protection and Affordable Care Act, ${ }^{40,41}$ empirical data are needed to understand the association between lower copayment and patient adherence. Although in our study the design of this tier reduction was not VBID, the tier reduction that resulted in decreased out-of-pocket expenses aligns with the principle of VBID, and findings suggest that elderly patients are also sensitive to the financial barrier to essential medications. Our study contributes to the growing evidence related to copayment and patient adherence, especially in the elderly population. In particular, this study is a unique addition to the body of evidence showing the association of lower copayments with increased adherence, since it specifically examined the effect of moving branded products to the lowest tier prior to patient expiration. This change exhibits the largest copayment reduction, as most of the VBID either eliminates the already low tier 1 copayment, or reduces the tier 2 copayment, but not quite to the tier 1 level. This reduction might explain the larger percentage point increase in adherence (5.91\%) compared with the prior studies $(2.56 \%-3.39 \%)$.

\section{Limitations}

The most important limitation of this study is selection bias. Although we examined existing members who were new users, patients who chose to continue to enroll in the health plan after the implementation of tier reduction in 2011 might be self-selected and different from those who decided to continue in 2010. For example, patients who chose to remain in the plan 
TABLE 2 Factors Associated with High Statin Adherence (PDC $\geq 0.8$ )

\begin{tabular}{|c|c|c|c|c|}
\hline & \multicolumn{2}{|c|}{$\begin{array}{c}\text { Tier-Reduction Group } \\
\text { (Atorvastatin/Rosuvastatin Users) } \\
\mathrm{N}=12,437 \\
\end{array}$} & \multicolumn{2}{|c|}{$\begin{array}{c}\text { Nontier-Reduction Group } \\
\text { (Other Statin Users) } \\
\mathrm{N}=15,116\end{array}$} \\
\hline & Odds Ratio & $95 \%$ CI & Odds Ratio & $95 \%$ CI \\
\hline 2011 cohort & $1.68^{\mathrm{a}}$ & $(1.55-1.82)^{\mathrm{a}}$ & 1.05 & $(0.98-1.12)$ \\
\hline 2010 cohort & Reference & & Reference & \\
\hline \multicolumn{5}{|l|}{ Age in years } \\
\hline $18-54$ & $0.79^{\mathrm{a}}$ & $(0.69-0.91)^{\mathrm{a}}$ & 0.89 & $(0.79-1.01)$ \\
\hline $55-64$ & $0.76^{\mathrm{a}}$ & $(0.64-0.90)^{\mathrm{a}}$ & 0.90 & $(0.78-1.04)$ \\
\hline $65-74$ & Reference & & Reference & \\
\hline $75-84$ & $1.13^{\mathrm{a}}$ & $(1.01-1.25)^{\mathrm{a}}$ & $1.21^{\mathrm{a}}$ & $(1.11-1.33)^{\mathrm{a}}$ \\
\hline $85+$ & $1.18^{\mathrm{a}}$ & $(1.03-1.34)^{\mathrm{a}}$ & 1.09 & $(0.97-1.22)$ \\
\hline Female & $0.82^{\mathrm{a}}$ & $(0.75-0.90)^{\mathrm{a}}$ & 0.97 & $(0.90-1.04)$ \\
\hline \multicolumn{5}{|l|}{ Region } \\
\hline Midwest & $1.30^{\mathrm{a}}$ & $(1.18-1.44)^{\mathrm{a}}$ & $1.37^{\mathrm{a}}$ & $(1.26-1.50)^{\mathrm{a}}$ \\
\hline Northeast & $1.57^{\mathrm{a}}$ & $(1.42-1.74)^{\mathrm{a}}$ & $1.44^{\mathrm{a}}$ & $(1.32-1.57)^{\mathrm{a}}$ \\
\hline South & Reference & & Reference & \\
\hline West & $1.42^{\mathrm{a}}$ & $(1.19-1.69)^{\mathrm{a}}$ & 1.05 & $(0.9-1.22)$ \\
\hline \multicolumn{5}{|l|}{ RxRisk score } \\
\hline Level 1 & Reference & & Reference & \\
\hline Level 2 & 0.91 & $(0.81-1.04)$ & $0.85^{\mathrm{a}}$ & $(0.76-0.95)^{\mathrm{a}}$ \\
\hline Level 3 & $0.71^{\mathrm{a}}$ & $(0.62-0.82)^{a}$ & $0.77^{\mathrm{a}}$ & $(0.68-0.86)^{\mathrm{a}}$ \\
\hline Level 4 & $0.49^{a}$ & $(0.43-0.56)^{\mathrm{a}}$ & $0.58^{\mathrm{a}}$ & $(0.52-0.65)^{\mathrm{a}}$ \\
\hline Statin prescription with 90-day supply (\%) & $1.42^{\mathrm{a}}$ & $(1.29-1.57)^{\mathrm{a}}$ & $1.49^{\mathrm{a}}$ & $(1.37-1.62)^{\mathrm{a}}$ \\
\hline
\end{tabular}

after tier reduction were younger and appeared to be healthier with lower levels of RxRisk score and a lower out-of-pocket prescription drug spending, resulting in fewer patients reaching the donut hole at the end of the 6-month study follow-up. In addition, more patients apparently initiated the 2 branded statins after tier reduction (56\% of all statin users) than before (33\%). Not having access to medical claims limited our ability to control for several health-related characteristics, and unobservable confounders may still exist and lead to biased estimates of the impact of tier reduction on adherence. For this reason, causality between tier reduction and adherence to statins cannot be drawn.

Several other limitations must be noted when interpreting the study results. Pharmacy claims might not reflect actual prescription consumption. Adherence patterns were evaluated for 6 months and might not be extrapolated to longer time periods. Because our study sample in the 2011 cohort was also enrolled in the previous year, our findings could not be generalizable to those new enrollees who switched from other plans. Similarly, we examined the impact of copayment reduction on members who newly initiated statins; the impact of copayment reduction on members continuing statin treatment was not evaluated. There are other financial factors that this study could not account for. Members may have different deductible thresholds that they need to meet, according to the plan they enrolled in, before they could receive the branded statins with lower copayment. Members may also have reached the donut hole (i.e., Medicare Part D coverage gap) at different times. It has been found that medication adherence decreases during the coverage gap period. ${ }^{42-44}$ In addition, patients may be on other medications that made them meet the deductable or reach the donut hole at different rates. Finally, we only evaluated Medicare beneficiaries who were enrolled in Medicare Part D plans, and the findings might not be generalizable to the Medicare beneficiaries who have private drug coverage.

As considerations of basing out-of-pocket costs on possible health benefits become more common in health plans, it is important to continue evaluating their effectiveness using empirical data. ${ }^{45}$ Future research should aim at assessing whether the effect will be sustainable in the long term and if the impact could be magnified by greater copayment reductions or even elimination of copayments. It would be particularly interesting to examine whether improved adherence to evidence-based medications could translate into better patient outcomes such as cholesterol control or reductions in hospitalizations for cardiovascular events. Our statin-specific findings provide an example that can be further researched in other therapeutic areas that have a low share of generics such as specialty medicine, human immunodeficiency virus infection, and certain rare diseases. In addition, it would be interesting to 


\section{FIGURE 4 Adjusted Differences in Mean PDC Comparing 2011 Cohort with 2010 Cohort $^{\text {a }}$}

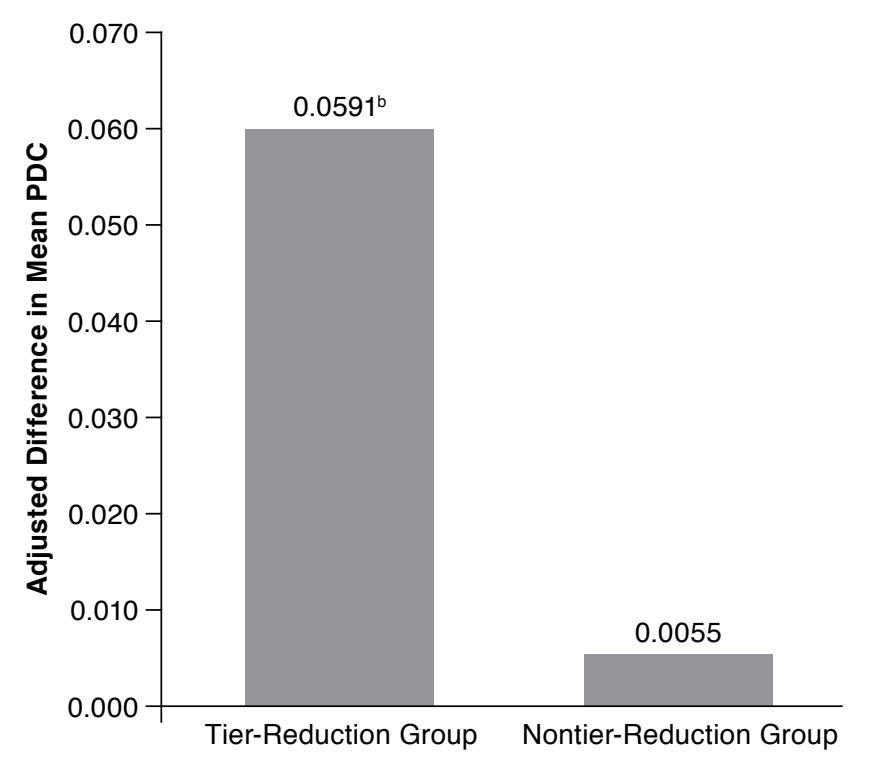

$\overline{{ }^{a} \text { Model adjusted for age, gender, region, RxRisk score category, and statin prescrip- }}$ tion with 90-day supply.

${ }^{b} P<0.05$ between 2010 and 2011 cohorts.

$P D C=$ proportion of days covered.

assess whether reducing or eliminating copays would have any impact on adherence within the context of the emerging health insurance exchange offerings.

\section{Conclusion}

Tier reduction resulting in lower copayments was associated with higher odds of branded statin adherence. Findings from this quasi-experimental study suggest that formulary strategies may improve medication adherence.

\section{Authors}

SHIH-YIN CHEN, PhD, is Research Scientist; YUAN-CHI LEE, MS, is Research Associate; and LUKE BOULANGER, MA, MBA, is Senior Research Scientist, Health Economics \& Epidemiology, Evidera, Lexington, Massachusetts. SONALI N. SHAH, RPh, MBA, MPH, is Director, Health Economics and Outcomes Research; JACK MARDEKIAN, PhD, is Outcomes Research Statistical Scientist; and ANDREAS KUZNIK, PhD, is Director, Global Health Economics and Outcomes Research, Pfizer Inc., New York, New York.

AUTHOR CORRESPONDENCE: Shih-Yin Chen, PhD, 430 Bedford St., Lexington, MA 02420. Tel.: 781.960.0302; Fax: 781.761.0147; E-mail: shih-yin.chen@evidera.com.

\section{DISCLOSURES}

This study was sponsored by Pfizer Inc. Chen, Lee, and Boulanger are employees of Evidera, which provides consulting and other research services to pharmaceutical, device, government, and nongovernmental organizations. In salaried positions, Evidera employees work with a variety of companies and organizations and are precluded from receiving payment or honoraria directly from these organizations for services rendered. Shah, Mardekian, and Kuznik are employees of Pfizer Inc. with ownership of stock in Pfizer Inc.

Study concept and design were contributed by Chen, Shah, and Kuznik. Data collection was the responsibility of Chen, Lee, Boulanger, and Mardekian, and data interpretation was performed by Chen and Kuznik, with the assistance of Shah, Lee, Boulanger, and Mardekian. The manuscript was written by Chen and Kuznik, with the assistance of Shah, Boulanger, Lee, and Mardekian, and revised by Chen, Shah, and Kuznik, with the assistance of Boulanger, Lee, and Mardekian.

\section{REFERENCES}

1. Heart Protection Study Collaborative Group. MRC/BHF Heart Protection Study of cholesterol lowering with simvastatin in 20,536 high-risk individuals: a randomised placebo-controlled trial. Lancet. 2002;360(9326):7-22. Available at: http://files.sld.cu/cdfc/files/2011/12/mrcbhf-heart-protectionstudy-of-cholesterol-lowering-with.pdf. Accessed September 30, 2013. 2. Downs JR, Clearfield M, Weis S, et al. Primary prevention of acute coronary events with lovastatin in men and women with average cholesterol levels: results of AFCAPS/TexCAPS. JAMA. 1998;279(20):1615-22. Available at: http://fundacionconfiar.com.ar/capacitacion/Clase_5/Levels\%20Results\%20 of\%20AFCAPSTexCAPS.pdf. Accessed September 30, 2013.

3. LaRosa JC, Grundy SM, Waters DD, et al. Intensive lipid lowering with atorvastatin in patients with stable coronary disease. N Engl J Med. 2005;352(14):1425-35. Available at: http://www.nejm.org/doi/full/10.1056/ NEJMoa050461. Accessed September 30, 2013.

4. Shepherd J, Cobbe SM, Ford I, et al. Prevention of coronary heart disease with pravastatin in men with hypercholesterolemia. West of Scotland Coronary Prevention Study Group. N Engl J Med. 1995;333(20):1301-07. Available at: http://www.nejm.org/doi/full/10.1056/ NEJM199511163332001\#t=article. Accessed September 30, 2013.

5. Chodick G, Shalev V, Gerber Y, et al. Long-term persistence with statin treatment in a not-for-profit health maintenance organization: a populationbased retrospective cohort study in Israel. Clin Ther. 2008;30(11):2167-79. 6. Benner JS, Glynn RJ, Mogun H, Neumann PJ, Weinstein MC, Avorn J. Long-term persistence in use of statin therapy in elderly patients. JAMA. 2002;288(4):455-61. Available at: http://jama.jamanetwork.com/article. aspx?articleid=195142. Accessed September 30, 2013.

7. Ellis JJ, Erickson SR, Stevenson JG, Bernstein SJ, Stiles RA, Fendrick AM. Suboptimal statin adherence and discontinuation in primary and secondary prevention populations. J Gen Intern Med. 2004;19(6):638-45. Available at: http://www.ncbi.nlm.nih.gov/pmc/articles/PMC1492382/. Accessed September 30, 2013.

8. Jackevicius CA, Mamdani M, Tu JV. Adherence with statin therapy in elderly patients with and without acute coronary syndromes. JAMA. 2002;288(4):462-67. Available at: https://jama.jamanetwork.com/article aspx?articleid=195144. Accessed September 30, 2013.

9. Vinker S, Shani M, Baevsky T, Elhayany A. Adherence with statins over 8 years in a usual care setting. Am J Manag Care. 2008;14(6):388-92. Available at: http://www.ajmc.com/publications/issue/2008/2008-06-voll4-n6/Jun083302p388-392\%. Accessed September 30, 2013.

10. Yeaw J, Benner JS, Walt JG, Sian S, Smith DB. Comparing adherence and persistence across 6 chronic medication classes. J Manag Care Pharm. 2009;15(9):728-40. Available at: http://www.amcp.org/data/jmcp/728-740.pdf. 11. Dragomir A, Côté R, White M, et al. Relationship between adherence level to statins, clinical issues and health-care costs in real-life clinical setting. Value Health. 2010;13(1):87-94.

12. Rublee DA, Chen SY, Mardekian J, Wu N, Rao P, Boulanger L. Evaluation of cardiovascular morbidity associated with adherence to atorvastatin therapy. Am J Ther. 2012;19(1):24-32. 
13. Corrao G, Conti V, Merlino L, Catapano AL, Mancia G. Results of a retrospective database analysis of adherence to statin therapy and risk of nonfatal ischemic heart disease in daily clinical practice in Italy. Clin Ther. 2010;32(2):300-10.

14. Foody JM, Joyce AT, Rudolph AE, Liu LZ, Benner JS. Persistence of atorvastatin and simvastatin among patients with and without prior cardiovascular diseases: a U.S. managed care study. Curr Med Res Opin. 2008;24(7):1987-2000

15. Amsterdam EA, Laslett L, Diercks D, Kirk JD. Reducing the knowledgepractice gap in the management of patients with cardiovascular disease. Prev Cardiol. 2002;5(1):12-15. Available at: http://onlinelibrary.wiley.com/ doi/10.1111/j.1520-037X.2002.0548.x/pdf. Accessed September 30, 2013. 16. Davidson MH. Differences between clinical trial efficacy and real-world effectiveness. Am J Manag Care. 2006;12(15 Suppl):S405-S11. Available at: http://www.ajmc.com/publications/supplement/2006/2006-11-voll2n15Suppl/Nov06-2395pS405-S411/. Accessed September 30, 2013

17. Frolkis JP, Pearce GL, Nambi V, Minor S, Sprecher DL. Statins do not meet expectations for lowering low-density lipoprotein cholesterol levels when used in clinical practice. Am J Med. 2002;113(8):625-29.

18. Bouchard MH, Dragomir A, Blais L, Bérard A, Pilon D, Perreault S. Impact of adherence to statins on coronary artery disease in primary prevention. Br J Clin Pharmacol. 2007;63(6):698-708. Available at: http://www. ncbi.nlm.nih.gov/pmc/articles/PMC2000596/. Accessed September 30, 2013 19. Perreault S, Dragomir A, Blais L, et al. Impact of better adherence to statin agents in the primary prevention of coronary artery disease. Eur J Clin Pharmacol. 2009;65(10):1013-24.

20. Aubert RE, Yao J, Xia F, Garavaglia SB. Is there a relationship between early statin compliance and a reduction in healthcare utilization? Am J Manag Care. 2010;16(6):459-66. Available at: http://www.ajmc.com/publications/issue/2010/2010-06-voll6-n06/AJMC_10jun_Aubert_459to466/. Accessed September 30, 2013.

21. Gibson TB, Mark TL, Axelsen K, Baser O, Rublee DA, McGuigan KA Impact of statin copayments on adherence and medical care utilization and expenditures. Am J Manag Care. 2006;12 Spec no.:SPl1-19. Available at: http://www.ajmc.com/publications/issue/2006/2006-12-voll2-n12SP/ Dec06-2415pSP11-SP19/. Accessed September 30, 2013.

22. Gibson TB, Mark TL, McGuigan KA, Axelsen K, Wang S. The effects of prescription drug copayments on statin adherence. Am J Manag Care. 2006;12(9):509-17. Available at: http://www.ajmc.com/publications/ issue/2006/2006-09-voll2-n9/Sep06-2359p509-517/. Accessed September $30,2013$.

23. Thiebaud P, Patel BV, Nichol MB. The demand for statin: the effect of copay on utilization and compliance. Health Econ. 2008;17(1):83-97.

24. Ye X, Gross CR, Schommer J, Cline R, St Peter WL. Association between copayment and adherence to statin treatment initiated after coronary heart disease hospitalization: a longitudinal, retrospective, cohort study. Clin Ther 2007;29(12):2748-57.

25. Goldman DP, Joyce GF, Zheng Y. Prescription drug cost sharing: associations with medication and medical utilization and spending and health. JAMA. 2007;298(1):61-69. Available at: http://jama.jamanetwork.com/article. aspx?articleid=207805. Accessed September 30, 2013.

26. Chernew ME, Shah MR, Wegh A, et al. Impact of decreasing copayments on medication adherence within a disease management environment. Health Aff (Millwood). 2008;27(1):103-12. Available at: http://content.healthaffairs. org/content/27/1/103.full?sid=12bf6683-0820-48f1-b6e6-2abc35e3a5cd. Accessed September 30, 2013.

27. Choudhry NK, Fischer MA, Avorn J, et al. At Pitney Bowes, value-based insurance design cut copayments and increased drug adherence. Health Aff (Millwood). 2010;29(11):1995-2001.

28. Gibson TB, Wang S, Kelly E, et al. A value-based insurance design program at a large company boosted medication adherence for employees with chronic illnesses. Health Aff (Millwood). 2011;30(1):109-17.

29. Maciejewski ML, Farley JF, Parker J, Wansink D. Copayment reductions generate greater medication adherence in targeted patients. Health Aff (Millwood). 2010;29(11):2002-08.
30. Rosamond W, Flegal K, Furie K, et al. Heart disease and stroke statistics-2008 update: a report from the American Heart Association Statistics Committee and Stroke Statistics Subcommittee. Circulation. 2008;117(4):e25146. Available at: http://circ.ahajournals.org/content/117/4/e25.long. Accessed September 30, 2013.

31. Alexander KP, Newby LK, Cannon CP, et al. Acute coronary care in the elderly, part I: Non-ST-segment-elevation acute coronary syndromes: a scientific statement for healthcare professionals from the American Heart Association Council on Clinical Cardiology: in collaboration with the Society of Geriatric Cardiology. Circulation. 2007;115(19):2549-69. Available at: http://circ.ahajournals.org/content/115/19/2549.long. Accessed September 30, 2013.

32. Candrilli SD, Kuznik A, Mendys PM, Wilson DJ. Prevalence and coexistence of cardiovascular comorbidities among the US dyslipidemic population aged $\geq 65$ years by lipid-lowering medication use status. Postgrad Med. 2010;122(5):142-49.

33. Gilman BH, Kautter J. Impact of multitiered copayments on the use and cost of prescription drugs among Medicare beneficiaries. Health Serv Res. 2008;43(2):478-95. Available at: http://www.ncbi.nlm.nih.gov/pmc/articles/ PMC2442369/pdf/hesr0043-0478.pdf. Accessed September 30, 2013.

34. Fishman PA, Goodman MJ, Hornbrook MC, Meenan RT, Bachman DJ, O'Keeffe Rosetti MC. Risk adjustment using automated ambulatory pharmacy data: the RxRisk model. Med Care. 2003;41(1):84-99.

35. Chang A, Liberman JN, Coulen C, Berger JE, Brennan TA. Value-based insurance design and antidiabetic medication adherence. Am J Pharm Benefits. 2010;2(1):39-44. Available at: http://www.ajmc.com/publications/ ajpb/2010/vol2_nol/Value-Based-Insurance-Design-and-AntidiabeticMedication-Adherence. Accessed September 30, 2013.

36. Zeng F, An JJ, Scully R, Barrington C, Patel BV, Nichol MB. The impact of value-based benefit design on adherence to diabetes medications: a propensity score-weighted difference in difference evaluation. Value Health. 2010;13(6):846-52. Available at: http://download.journals.elsevierhealth. com/pdfs/journals/1098-3015/PIIS1098301511718113.pdf. Accessed September 30, 2013.

37. Leibowitz A, Manning WG, Newhouse JP. The demand for prescription drugs as a function of cost-sharing. Soc Sci Med. 1985;21(10):1063-69.

38. Gellad WF, Grenard JL, Marcum ZA. A systematic review of barriers to medication adherence in the elderly: looking beyond cost and regimen complexity. Am J Geriatr Pharmacother. 2011;9(1):11-23. Available at: http:// www.ncbi.nlm.nih.gov/pmc/articles/PMC3084587/pdf/nihms-278994.pdf. Accessed September 30, 2013.

39. Fendrick AM, Smith DG, Chernew ME, Shah SN. A benefit-based copay for prescription drugs: patient contribution based on total benefits, not drug acquisition cost. Am J Manag Care. 2001;7(9):861-67.

40. U.S. Congress. S1040, Seniors Medication Copayment Reduction Act of 2009. 11lth Congress, 1st Session. May 14, 2009. Available at: http://www. govtrack.us/congress/bills/11l/s1040/text. Accessed September 30, 2013. 41. U.S. Congress. HR 3590, Patient Protection and Affordable Care Act. 111th Congress, 1st Session. Section 2712 (c). August 25, 2010. Available at: http://www.govtrack.us/congress/bills/111/hr3590/text. Accessed September $30,2013$.

42. Polinski JM, Shrank WH, Huskamp HA, Glynn RJ, Liberman JN, Schneeweiss $S$. Changes in drug utilization during a gap in insurance coverage: an examination of the medicare Part D coverage gap. PLoS Med. 2011;8(8):e1001075. Available at: http://www.plosmedicine.org/article/ info\%3Adoi\%2F10.1371\%2Fjournal.pmed.1001075. Accessed September 30, 2013.

43. Li P, McElligott S, Bergquist H, Schwartz JS, Doshi JA. Effect of the Medicare Part D coverage gap on medication use among patients with hypertension and hyperlipidemia. Ann Intern Med. 2012;156(11):776-84, W263-69. 44. Fung V, Mangione CM, Huang J, et al. Falling into the coverage gap: Part D drug costs and adherence for Medicare Advantage prescription drug plan beneficiaries with diabetes. Health Serv Res. 2010;45(2):355-75. Available at: http://www.ncbi.nlm.nih.gov/pmc/articles/PMC2838150/. Accessed September 30, 2013.

45. Appleby J. Carrot-and-stick health plans aims to cut costs. Kaiser Health News. March 11, 2010. Available at: http://www.kaiserhealthnews. org/Stories/2010/March/11/value-based-health-insurance.aspx. Accessed September 30, 2013. 


\section{APPENDIX A Sensitivity Analysis of Factors Associated with High Statin Adherence} (PDC $\geq 0.8$ ) by Excluding Members Receiving 90-Day Supply

\begin{tabular}{|c|c|c|c|c|}
\hline & \multicolumn{2}{|c|}{$\begin{array}{l}\text { Tier-Reduction Group } \\
\text { (Atorvastatin/Rosuvastatin Users) } \\
\qquad \mathrm{N}=9,670\end{array}$} & \multicolumn{2}{|c|}{$\begin{array}{c}\text { Nontier-Reduction Group } \\
\text { (Other Statin Users) } \\
\mathrm{N}=11,521 \\
\end{array}$} \\
\hline & Odds Ratio & $95 \%$ CI & Odds Ratio & $95 \% \mathrm{CI}$ \\
\hline 2011 cohort & $1.61^{\mathrm{a}}$ & $(1.47-1.76)^{\mathrm{a}}$ & 1.03 & $(0.95-1.12)$ \\
\hline 2010 cohort & Reference & & Reference & \\
\hline \multicolumn{5}{|l|}{ Age in years } \\
\hline $18-54$ & $0.83^{a}$ & $(0.71-0.97)^{a}$ & 0.88 & $(0.76-1.01)$ \\
\hline $55-64$ & $0.80^{a}$ & $(0.66-0.97)^{\mathrm{a}}$ & 0.88 & $(0.75-1.03)$ \\
\hline $65-74$ & Reference & & Reference & \\
\hline $75-84$ & $1.17^{\mathrm{a}}$ & $(1.04-1.32)^{\mathrm{a}}$ & $1.19^{\mathrm{a}}$ & $(1.07-1.32)^{\mathrm{a}}$ \\
\hline $85+$ & $1.21^{\mathrm{a}}$ & $(1.04-1.40)^{\mathrm{a}}$ & 1.09 & $(0.96-1.23)$ \\
\hline Female & $0.82^{a}$ & $(0.74-0.90)^{\mathrm{a}}$ & 0.96 & $(0.88-1.05)$ \\
\hline \multicolumn{5}{|l|}{ Region } \\
\hline Midwest & $1.34^{\mathrm{a}}$ & $(1.19-1.50)^{\mathrm{a}}$ & $1.43^{\mathrm{a}}$ & $(1.29-1.59)^{\mathrm{a}}$ \\
\hline Northeast & $1.62^{\mathrm{a}}$ & $(1.45-1.81)^{a}$ & $1.51^{\mathrm{a}}$ & $(1.38-1.67)^{\mathrm{a}}$ \\
\hline South & Reference & & Reference & \\
\hline West & $1.42^{\mathrm{a}}$ & $(1.17-1.74)^{\mathrm{a}}$ & 1.13 & $(0.95-1.34)$ \\
\hline \multicolumn{5}{|l|}{ RxRisk score } \\
\hline Level 1 & Reference & & Reference & \\
\hline Level 2 & 0.94 & $(0.82-1.08)$ & $0.87^{\mathrm{a}}$ & $(0.77-0.99)^{a}$ \\
\hline Level 3 & $0.79^{a}$ & $(0.68-0.93)^{\mathrm{a}}$ & $0.80^{\mathrm{a}}$ & $(0.70-0.92)^{\mathrm{a}}$ \\
\hline Level 4 & $0.53^{a}$ & $(0.45-0.62)^{a}$ & $0.60^{\mathrm{a}}$ & $(0.53-0.69)^{a}$ \\
\hline
\end{tabular}




\section{APPENDIX B Sensitivity Analysis of Factors Associated with High Statin Adherence (PDC $\geq 0.8$ ) by Excluding} Patients with Statin Prescription Filled Outside of Retail, Home, or Outpatient Settings

\begin{tabular}{|c|c|c|c|c|}
\hline & \multicolumn{2}{|c|}{$\begin{array}{c}\text { Tier-Reduction Group } \\
\text { (Atorvastatin/Rosuvastatin Users) } \\
\qquad \mathrm{N}=12,242\end{array}$} & \multicolumn{2}{|c|}{$\begin{array}{c}\text { Nontier-Reduction Group } \\
\text { (Other Statin Users) } \\
\mathrm{N}=14,573\end{array}$} \\
\hline & Odds Ratio & $95 \%$ CI & Odds Ratio & $95 \%$ CI \\
\hline 2011 cohort & $1.68^{a}$ & $(1.55-1.83)^{\mathrm{a}}$ & 1.06 & $(0.98-1.13)$ \\
\hline 2010 cohort & Reference & & Reference & \\
\hline \multicolumn{5}{|l|}{ Age in years } \\
\hline $18-54$ & $0.79^{a}$ & $(0.68-0.91)^{\mathrm{a}}$ & 0.90 & $(0.79-1.01)$ \\
\hline $55-64$ & $0.76^{\mathrm{a}}$ & $(0.64-0.90)^{\mathrm{a}}$ & 0.90 & $(0.79-1.04)$ \\
\hline $65-74$ & Reference & & Reference & \\
\hline $75-84$ & $1.12^{\mathrm{a}}$ & $(1.01-1.25)^{\mathrm{a}}$ & $1.22^{\mathrm{a}}$ & $(1.11-1.34)^{\mathrm{a}}$ \\
\hline $85+$ & $1.18^{\mathrm{a}}$ & $(1.03-1.35)^{\mathrm{a}}$ & 1.08 & $(0.97-1.21)$ \\
\hline Female & $0.82^{\mathrm{a}}$ & $(0.75-0.90)^{\mathrm{a}}$ & 0.96 & $(0.89-1.04)$ \\
\hline \multicolumn{5}{|l|}{ Region } \\
\hline Midwest & $1.31^{\mathrm{a}}$ & $(1.19-1.45)^{\mathrm{a}}$ & $1.38^{\mathrm{a}}$ & $(1.26-1.51)^{\mathrm{a}}$ \\
\hline Northeast & $1.57^{\mathrm{a}}$ & $(1.42-1.74)^{\mathrm{a}}$ & $1.44^{\mathrm{a}}$ & $(1.32-1.58)^{\mathrm{a}}$ \\
\hline South & Reference & & Reference & \\
\hline West & $1.42^{\mathrm{a}}$ & $(1.19-1.69)^{\mathrm{a}}$ & 1.04 & $(0.89-1.20)$ \\
\hline \multicolumn{5}{|l|}{ RxRisk score } \\
\hline Level 1 & Reference & & Reference & \\
\hline Level 2 & 0.92 & $(0.81-1.05)$ & $0.86^{\mathrm{a}}$ & $(0.77-0.97)^{\mathrm{a}}$ \\
\hline Level 3 & $0.71^{\mathrm{a}}$ & $(0.62-0.82)^{\mathrm{a}}$ & $0.77^{\mathrm{a}}$ & $(0.68-0.87)^{a}$ \\
\hline Level 4 & $0.48^{a}$ & $(0.42-0.55)^{\mathrm{a}}$ & $0.58^{a}$ & $(0.52-0.65)^{\mathrm{a}}$ \\
\hline Received any statin claims with 90-day supply & $1.42^{\mathrm{a}}$ & $(1.29-1.57)^{\mathrm{a}}$ & $1.49^{a}$ & $(1.37-1.62)^{\mathrm{a}}$ \\
\hline
\end{tabular}

